\title{
The efficacy and safety of liraglutide in the obese, non-diabetic individuals: a systematic review and meta-analysis
}

\author{
Pei Zhang ${ }^{1}$, Yu Liu ${ }^{1}$, Yuan Ren ${ }^{1}$, Jie Bai ${ }^{1}$, Guangzhen Zhang ${ }^{1}$, Yuanshan Cui ${ }^{2,3}$
}

\begin{abstract}
1. Department of Endocrinology, Liaocheng People's Hospital, NO.67 West Dongchang Road, 252000 Liaocheng, China.

2. Department of Urology, Yantai Yuhuangding Hospital, NO.20 East Yuhuangding Road, 264000 Yantai, China.

3. Department of Urology, Beijing Tian Tan Hospital, Capital Medical University, Beijing, China.
\end{abstract}

\begin{abstract}
Background: Liraglutide has been shown to improve glucose tolerance and lose weight in individuals with type 2 diabetes. To date, no meta-analysis of liraglutide's safety and efficacy in individuals without diabetes has been conducted.

Objectives: The aim of this study is to carry out a meta-analysis to assess the efficacy and safety of liraglutide in the obese, non-diabetic individuals.

Methods: A literature review was performed to identify all published randomised control trials (RCT) of liraglutide for the treatment of obesity in non-diabetic individuals. The search included the following databases: EMBASE, MEDLINE and the Cochrane Controlled Trials Register.

Results: We included five publications involving a total of 4,754 patients that compared liraglutide with placebo and found that liraglutide to be an effective and safe treatment for weight loss in individuals without diabetes. Primary efficacy end points: mean weight loss (MD $=-5.52,95 \% \mathrm{CI}=-5.93$ to $-5.11, \mathrm{p}<0.00001)$; lost more than $5 \%$ of body weight $(\mathrm{OR}=5.46,95 \% \mathrm{CI}=3.57$ to 8.34, $\mathrm{p}<0.00001$ ) and key secondary efficacy end points: SBP decreased (the MD $=-2.56,95 \% \mathrm{CI}=-3.28$ to $-1.84, \mathrm{p}<0.00001$ ). Safety assessments included the proportion of individuals who were withdrawn due to AE (OR $=2.85,95 \% \mathrm{CI}=0.84$ to 9.62 , $\mathrm{p}=0.009)$, and nausea indicated that liraglutide was well tolerated.
\end{abstract}

Conclusion: This systematic review and meta-analysis indicates that liraglutide to be an effective and safe treatment for weight loss in the obese, non-diabetic individuals.

Keywords: liraglutide, weight loss, meta-analysis.

DOI: https://dx.doi.org/10.4314/ahs.v19i3.35

Cite as: Zhang P, Lin Y, Ren Y, Bai J, Zhang G, Cui Y. The efficacy and safety of liraglutide in the obese, non-diabetic individuals: a systematic review and meta-analysis. Afri Health Sci. 2019;19(3): 2591-2599. bttps:// dx.doi.org/10.4314/abs.v19i3.35

\section{Introduction}

Over the past few decades, the rate of obesity has risen three-fold and is more than $30 \%$ in some European countries ${ }^{1}$. Around $50 \%$ of all adults in Europe are classified as overweight ${ }^{2,3}$. Obesity has become a global epi-

\section{Corresponding author:}

Yuanshan Cui,

Department of Urology,

Yantai Yuhuangding Hospital,

NO.20 East Yuhuangding Road,

264000 Yantai, China.

Phone number: 0535-6691999-83823

Email: doctorcuiys@163.com demic that affects diverse societies across developed and developing countries ${ }^{4}$. Obesity rates correlate well with recent developments such as incessant enticements to sit and an unprecedented availability, at low or no cost, of foods and beverages rich in poorly satiating calories ${ }^{5}$. These rapid environmental changes interact with preexisting genetic tendencies, yet in a timescale so brief as to outstrip evolution ${ }^{6}$. Obesity increases the risk of hypertension, diabetes, and atherosclerosis, all risk factors for the leading cause of death worldwide-cardiovascular disease $^{7,8}$. Moreover, obesity is associated with a reduced quality of life ${ }^{9,10}$.

However, weight loss is never an easy goal to achieve or maintain. Although numerous randomized trials of life-

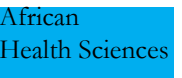

C) 2019 Zhang et al. Licensee African Health Sciences. This is an Open Access article distributed under the terms of the Creative commons Attribution License (https://creativecommons.org/licenses/BY/4.0), which permits unrestricted use, distribution, and reproduction in any medium, provided the original work is properly cited.

African Health Sciences Vol 19 Issue 3, September, 2019 
style modification, medications, and bariatric surgery have shown that weight loss reduces morbidity, most patients cannot sustain sufficient weight loss ${ }^{11}$. Lifestyle modifications, restricted-calorie diet and increased physical activity, are easily operated but hardly endurable. Few safe and effective drugs are currently available for the treatment of obesity because of side effects and inadequate efficacy, especially in the long term. Bariatric surgery results in the most weight loss and the highest rates of remission of type 2 diabetes, but the potential side effects are of concern $^{12}$. Liraglutide is a glucagon-like peptide-1 (GLP1) analogue with a $97 \%$ structural homology to human GLP-1, a gut-derived incretin hormone has been shown to improve glucose tolerance and lose weight in individuals with type 2 diabetes (T2DM ${ }^{13}$. This provided a rationale for investigating liraglutide as a treatment for obese, non-diabetic individuals.

Only a few clinical studies have demonstrated the effect of liraglutide action in obese, non-diabetic individuals. To date, no meta-analysis of liraglutide's safety and efficacy in individuals without diabetes has been conducted. The goal of the present study was toerform a meta-analysis to evaluate the efficacy and safety of liraglutide in obese, non-diabetic individuals.

\section{Materials and methods Search strategy}

All randomized controlled trials reporting the effect of liraglutide in weight management for obese, non-diabetic individuals were systematically searched in the Medline, Embase and Cochrane Controlled Trials Register databases until May 2018. The search strategy was designed to identify all possible studies that included the following key words: "liraglutide" AND "weight loss" AND "non-diabetic" AND "randomized controlled trial". All related studies published in English language were included. In addition, a manual search was conducted to investigate the relevant references of the retrieved publications. 2.2. Inclusion criteria, trial selection, exclusion criteria and data extraction

All the selected articles were screened according to the following criteria for inclusion: (1) The study design included treatment with liraglutide for obese, non-diabetic individuals; (2) the study provided accurate data that could be analyzed, including the total number of subjects and the values of each index; and (3) the full text of the study could be accessed. If the same author reported various articles sharing the identical case series, only the study with the most persons was used, and if the same research was published in different journals, only the most recent article was included for analysis. Exclusion criteria were as follows: (1) not randomized controlled trial; (2) case reports, reviews, or meta-analysis; (3)studies that were based on incomplete raw data. A flow diagram of the study selection process is presented in Figure 1. Two investigators retrieved data from the literature based on the same inclusion standards and then performed a crosscheck. Any disagreement was resolved by discussion or by a third investigator. Usable information was collected from each study: (1) the name of the first author and the publication year; (2) the study design and sample size; (3) the therapy that the patients received; (4) the country in which the study was conducted; and (5) data including the mean weight loss, the proportion of lost more than $5 \%$ of body weight, systolic blood pressure (SBP) decreased, the proportion of individuals who withdrawn due to adverse event (AE) and nausea.

\section{Quality assessment Data extraction}

Risk of bias was rated per outcome according to Cochrane guidelines ${ }^{14}$ and is summarised in Fig. 1. The majority of studies were rated as low risk of bias arising from randomisation; having adequate random sequence generation and allocation concealment and few baseline imbalances. There was generally low risk of bias due to deviations from intended interventions

\section{Statistical analysis and meta-analysis}

Relevant data recruited in the meta-analysis were compared by using RevMan v.5.1.0. (Cochrane Collaboration, Oxford, UK $)^{14}$. The mean weight loss, the proportion of lost more than $5 \%$ of body weight and SBP decreased were determined as differences between baseline (study entry) and study completion. We used the fixed effects model (Mantel-Haenszel method) and random effects model (DerSimonian and Laird method) to evaluate the mean difference (MD) for continuous data and the relative risk for dichotomous results pooled across studies with corresponding $95 \%$ confidence interval $(\mathrm{CI})^{15}$. The 
study was considered to be homogeneous only when the analysis showed $\mathrm{p}>0.05$ and then a fixed-effect model was chosen for meta-analysis; otherwise, a random-effect model was more appropriate. Inconsistency across studies was quantified by $\mathrm{I}^{2}$ statistic, which describes the true extent of heterogeneity but not due to chance in results 16. $\mathrm{I}^{2}$ values range from 0 to $100 \%$, it represents a low level of heterogeneity if $\mathrm{I}^{2}<25 \%$, and a significant inconsistency existing if $\mathrm{I}^{2}>50 \%$.

\section{Results}

Characteristics of the individual studies

The database search found 285 articles that could have been included in our meta-analysis. Based on the inclusion and exclusion criteria, 246 articles were excluded after reading the titles and abstracts of the articles. 34 articles were not randomized controlled trials. In all, 5 articles $^{17-21}$, reporting data from a total of 5 RCTs that compared liraglutide with placebo, were included in the analysis (Fig. 2). The relevant information about the included articles is listed in Table 1.

Table 1: Study and patient characteristics.

\begin{tabular}{|c|c|c|c|c|c|c|c|c|c|}
\hline \multirow[b]{2}{*}{ Study } & \multirow{2}{*}{$\begin{array}{l}\text { Therapy in } \\
\text { experiment } \\
\text { al group }\end{array}$} & \multirow{2}{*}{$\begin{array}{l}\text { Therapy } \\
\text { in } \\
\text { control } \\
\text { group }\end{array}$} & \multirow[b]{2}{*}{ Country } & \multicolumn{2}{|c|}{ Sample size } & \multirow{2}{*}{$\begin{array}{l}\text { Administration } \\
\text { method }\end{array}$} & \multirow{2}{*}{$\begin{array}{l}\text { Duration } \\
\quad \text { of } \\
\text { treatment }\end{array}$} & \multirow{2}{*}{$\begin{array}{l}\text { Dosage } \\
(\mathrm{mg})\end{array}$} & \multirow{2}{*}{$\begin{array}{l}\text { Inclusion } \mathrm{p} \\
\text { opulation }\end{array}$} \\
\hline & & & & experimental & Control & & & & \\
\hline $\begin{array}{l}\text { up A } 2009 \\
{[17]}\end{array}$ & Liraglutide & Placebo & $\begin{array}{l}19 \text { sites } \\
\text { in Europe }\end{array}$ & 93 & 98 & subcutaneous & 20 weeks & 3 & $\begin{array}{c}\text { aged } 18- \\
65 \text { years, with } \\
\text { BMI of } 30-40 \\
\mathrm{~kg} / \mathrm{m}^{2}, \text { stable } \\
\text { body weight } \\
\text { and fasting } \\
\text { plasma } \\
\text { glucose of less } \\
\text { than } 7 \mathrm{mmol} / \mathrm{L}\end{array}$ \\
\hline $\begin{array}{l}\text { SH } 2013 \\
{[18]}\end{array}$ & Liraglutide & Placebo & US & 24 & 27 & subcutaneous & 14 weeks & 3 & $\begin{array}{c}\text { aged } 40- \\
70 \text { years, with } \\
\text { BMI of } 27-40 \\
\mathrm{~kg} / \mathrm{m}^{2} \text { with } \\
\text { prediabetes }\end{array}$ \\
\hline $\begin{array}{l}\text { Idden TA } \\
\text { ग13 [19] }\end{array}$ & Liraglutide & Placebo & $\begin{array}{l}\text { US and } \\
\text { Canada }\end{array}$ & 212 & 210 & subcutaneous & 56 weeks & 3 & $\begin{array}{c}\text { aged } \geq 18 \\
\text { years, with } \\
\text { stable body } \\
\text { weight and } \\
\text { BMI } \geq 30 \mathrm{~kg} / \mathrm{m}\end{array}$ \\
\hline $\begin{array}{l}\text { Sunyer X } \\
\text { ग15 [20] }\end{array}$ & Liraglutide & Placebo & $\begin{array}{l}\text { Europe, } \\
\text { North } \\
\text { America, } \\
\text { South } \\
\text { America, } \\
\text { Asia, } \\
\text { Africa, } \\
\text { and } \\
\text { Australia }\end{array}$ & 2487 & 1244 & subcutaneous & 56 weeks & 3 & $\begin{array}{c}\text { aged } \geq 18 \\
\text { years, with } \\
\text { stable body } \\
\text { weight and } \\
\text { BMI } \geq 30 \mathrm{~kg} / \mathrm{m}\end{array}$ \\
\hline $\begin{array}{l}\operatorname{man} A 201 \\
6[21]\end{array}$ & Liraglutide & Placebo & $\begin{array}{l}\text { US and } \\
\text { Canada }\end{array}$ & 180 & 179 & subcutaneous & 32 weeks & 3 & $\begin{array}{c}\text { aged } 18-64 \\
\text { years, with } \\
\text { stable body } \\
\text { weight and } \\
\text { BMI } \geq 30 \mathrm{~kg} / \mathrm{m}\end{array}$ \\
\hline
\end{tabular}




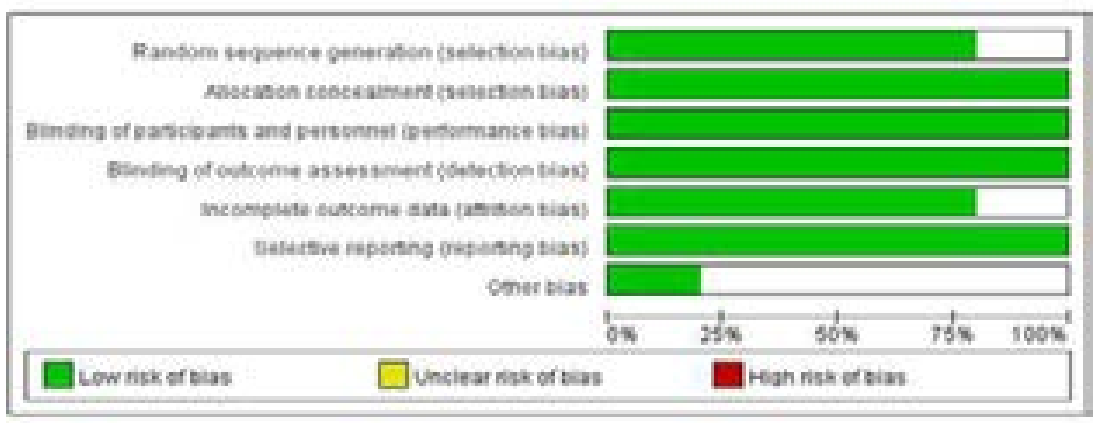

Figure 1 Kisk of bias of the individeal studiss.

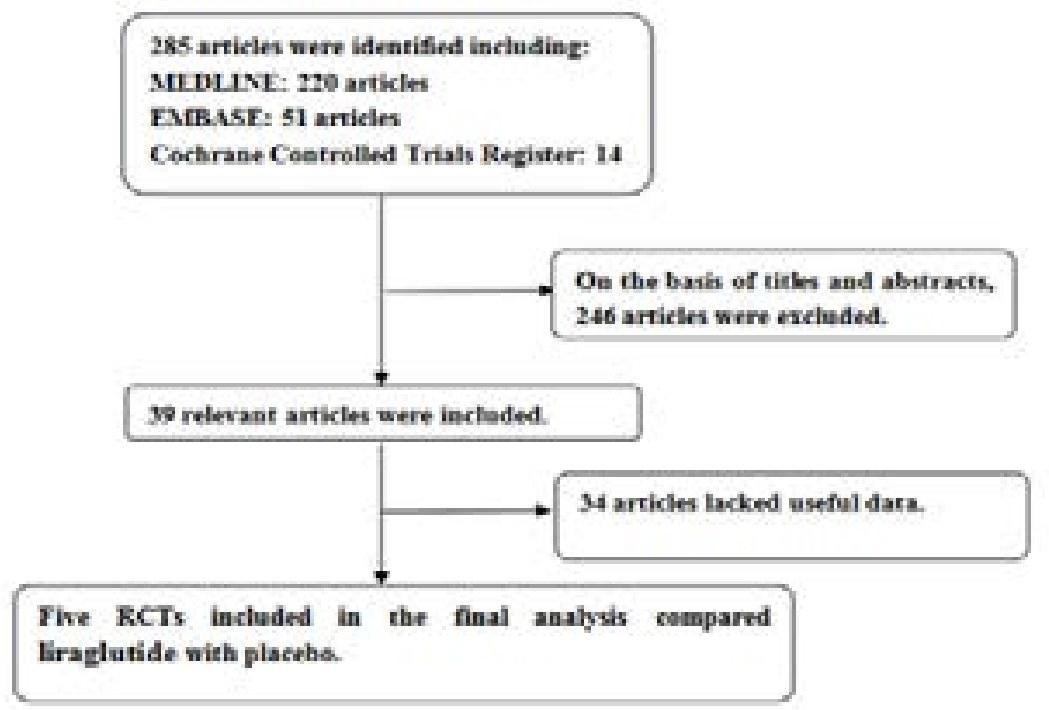

Figure 2 A flow diagram of the study selection process.

RCTr randomized controlled trial

Quality of the individual studies

One study performed IT'T analysis. Each included a power calculation to determine the optimal sample size (Table
2). The funnel plot provided a qualitative estimation of publication bias of the studies, and no evidence of bias was found (Fig. 3). 
Table 2: Quality assessment of individual study.

\begin{tabular}{c|c|c|c|c|c|c|c|}
\hline Study & $\begin{array}{c}\text { Allocation } \\
\text { sequence ge } \\
\text { neration }\end{array}$ & $\begin{array}{c}\text { Allocation } \\
\text { concealment }\end{array}$ & Blinding & $\begin{array}{c}\text { Loss to } \\
\text { follow-up }\end{array}$ & $\begin{array}{c}\text { Calculation } \\
\text { of sample } \\
\text { size }\end{array}$ & $\begin{array}{c}\text { Statistical } \\
\text { analysis }\end{array}$ & $\begin{array}{c}\text { ITT } \\
\text { analysis }\end{array}$ \\
\hline quality \\
tstrup A 2009 [17]
\end{tabular}

A - all quality criteria met (adequate): low risk of bias. B - one or more of the quality criteria only partly met (unclear): moderate risk of bias.

$\mathrm{C}$ - one or more criteria not met (inadequate or not used): high risk of bias.

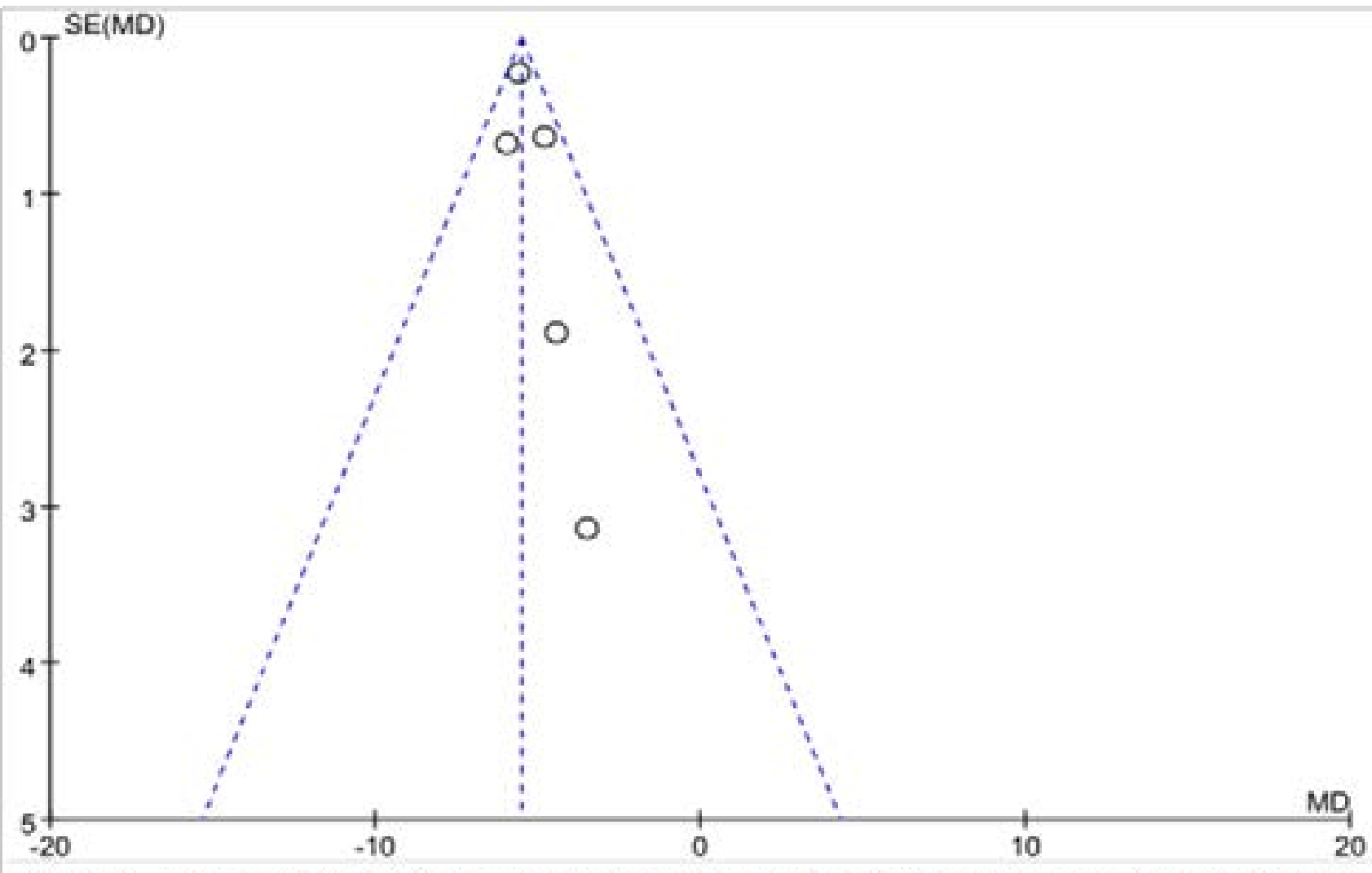

Figzure 3 Funnel plot of the studies represented in the meta-analysis. MDi mean difference, SE: standard error 


\section{Liraglutide versus placebo \\ Mean weight loss}

Five RCTs, representing 4,754 participants $(2,996$ in the liraglutide group and 1,758 in the placebo group) (Fig. 4) were identified. According to our analysis, no heterogeneity was found among the trials (Fig. 4), thus a fixed-ef- fects model was thus chosen for the analysis. Based on our analysis, the pooled estimate of MD was -5.52 , and the $95 \%$ CI was -5.93 to $-5.51(\mathrm{p}<0.00001)$. This result suggests that liraglutide showed statistically significantly greater reduces in the mean weight loss compared with placebo.

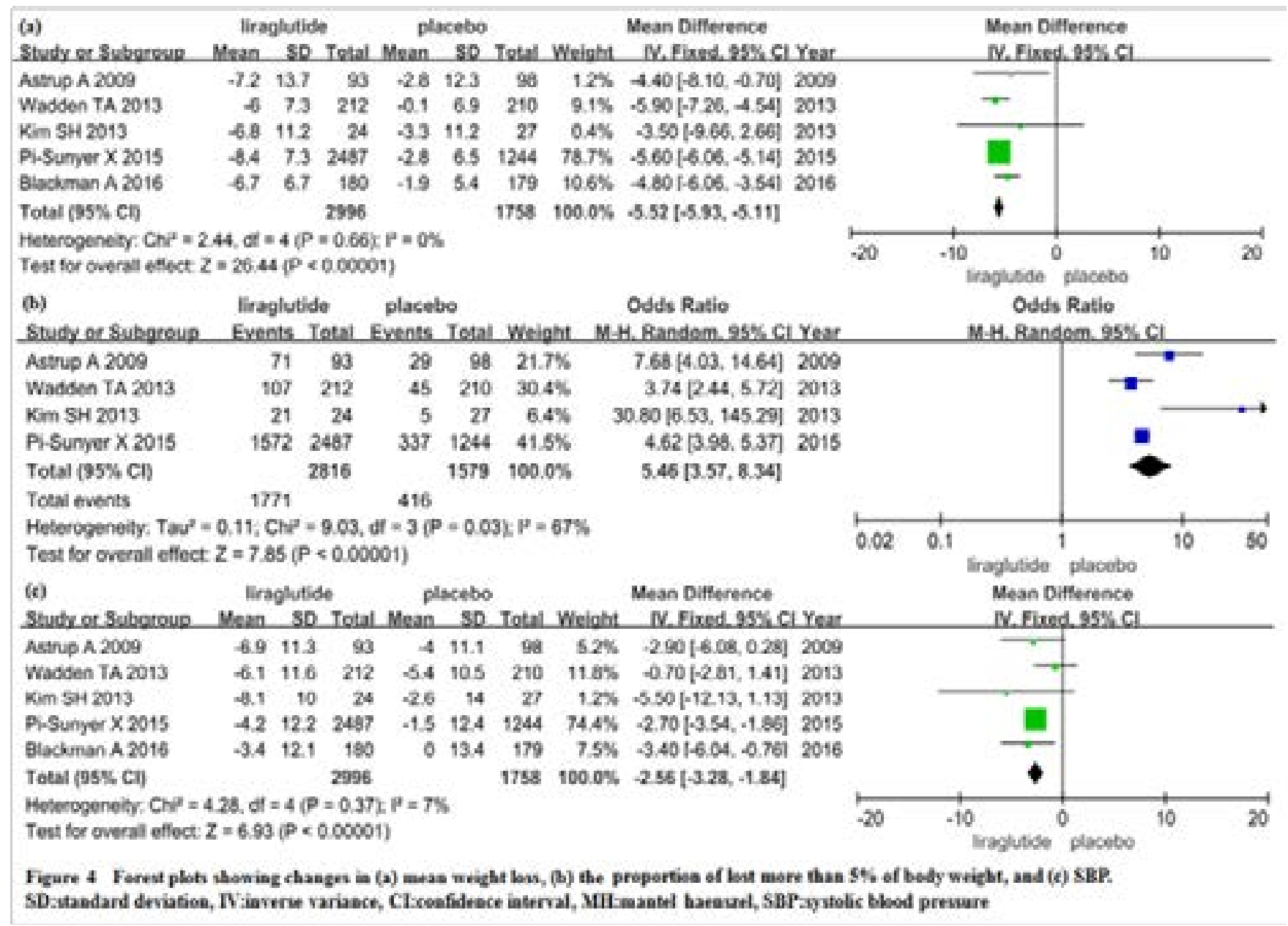

\section{Lost more than $5 \%$ of body weight}

The four RCTs included the proportion of lost more than $5 \%$ of body weight data representing 4,395 participants (2,816 in the liraglutide group and 1,579 in the placebo group) (Fig. 4). The heterogeneity test showed $\mathrm{P}=0.03$, so we adopted the random-effects model (Fig. 4), the OR was 5.46 , and the $95 \%$ CI was 3.57 to 8.34 ( $p<0.00001)$. This result suggests that liraglutide showed statistically significantly greater decreases in the proportion of lost more than $5 \%$ of body weight compared with placebo.

\section{SBP}

Five RCTs included the SBP data representing a cohort of 4,754 participants $(2,996$ in the liraglutide group and
1,758 in the placebo group) (Fig. 4). The fixed-effects estimate of the MD was -2.56 , and the $95 \%$ CI was -3.28 to $-1.84(\mathrm{p}<0.00001)$. This result suggests that liraglutide had significantly greater reduces in SBP.

\section{Withdrawn due to $\mathrm{AE}$}

Four RCTs included the proportion of individuals who withdrawn due to AE data representing a cohort of 4,703 participants (2,972 in the liraglutide group and 1,731 in the placebo group) (Fig. 5). The random-effects estimate of the OR was 2.85 , and the $95 \%$ CI was 0.84 to 9.62 $(p=0.09)$. The result suggests that liraglutide and placebo were similar in terms of the incidence of withdrawn due to $\mathrm{AE}$. 


\section{Nausea}

Four RCTs included the nausea data representing a cohort of 4,703 participants (2,972 in the liraglutide group and 1,731 in the placebo group) (Fig. 5). The heterogeneity test showed $\mathrm{P}<0.05$, so we adopted the random-effects model (Fig. 5), the OR was 5.04, and the $95 \%$ CI was 3.34 to $7.6(\mathrm{p}<0.00001)$. The result suggests that nausea was more common among those patients treated with liraglutide as compared to those treated with placebo.

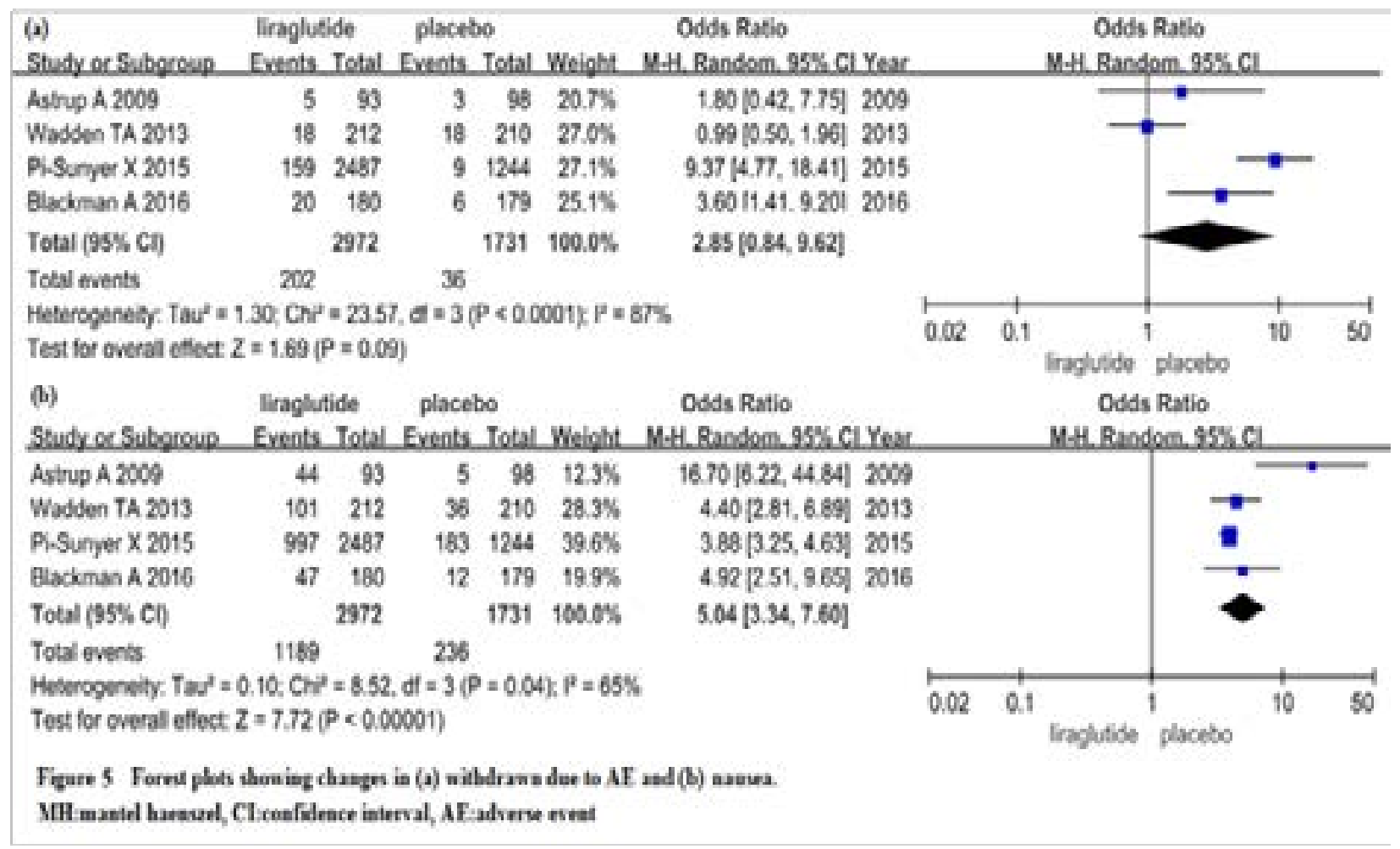

\section{Discussion}

According to the data retrieved from five RCTs of at least 12 weeks of consistent therapy, our systematic review and quantitative meta-analysis summarizes the evidence regarding the efficacy and safety of liraglutide for the treatment of obese in non-diabetic individuals. This study reveals that liraglutide $3.0 \mathrm{mg}$ once daily is superior to placebo in reducing weight and the proportion of lost more than $5 \%$ of body weight and SBP.

Liraglutide treatment was associated with reductions in SBP which is a cardiometabolic risk factor. Four of the included RCTs demonstrated that there were statistically significant, although sometimes quantitatively modest, improvements in glycemic control, fasting insulin concentrations, cardiometabolic markers, and quality of life measures. Besides, Pi Sunyer et al. testified the prevalence of prediabetes was significantly lower in the liraglutide group than in the placebo group at week 56, a finding that was consistent with the improvement in glycemic control with liraglutide. T2DM developed in much less patients in the liraglutide group than in the placebo group during the course of treatment ${ }^{20}$.

Obesity once indicated prosperity and was considered to be attractive. But now we know that overnutrition and underexertion beget a cluster of seemingly unrelated problems labeled "the metabolic syndrome," which includes visceral abdominal obesity, dyslipoproteinemia, dysglycemia, or hypertension. Although obesity is associated with resistance to the plasma glucose lowering actions of insulin, many other metabolic pathways still remain responsive to insulin ${ }^{22}$. Liraglutide is a GLP-1 analogue which is approved for the treatment of T2DM at doses up to $1.8 \mathrm{mg}$ once daily ${ }^{13}$. Weight loss with liraglutide is dose-dependent up to $3.0 \mathrm{mg}$ once daily and is mediated by reduced appetite and energy intake rather than by increased energy expenditure ${ }^{23}$. 
The underlying mechanisms that mediate the effects of weight loss of liraglutide are most probably a combination of effects on the gastrointestinal tract and brain. $\mathrm{Na}$ tive GLP-1 has a short elimination half-life of 1-2 min, whereas liraglutide has a long half-life of about $13 \mathrm{~h}$ and can be administered once a day by subcutaneous injection. Native GLP-1 suppresses appetite and energy intake in both normal-weight and obese individuals, and delays gastric emptying ${ }^{24}$. GLP-1 receptors are expressed in several brainstem nuclei involved in appetite regulation, and subcutaneously administered liraglutide might also reach these sites ${ }^{25}$. Can J van et al. did a RCT which demonstrated that liraglutide-induced weight loss appears to be mediated by reduced appetite and energy intake rather than increased energy expenditure ${ }^{23}$.

Safety data from the trials in this meta-analysis suggest that liraglutide administration was generally well-tolerated. Although the proportion of women who experienced an $\mathrm{AE}$ such as nausea were significantly more frequent with liraglutide use than with placebo, they were mostly mild or moderate in severity and discontinuation due to AEs occurred no more frequently with liraglutide use than with placebo. The most commonly reported treatment emergent AEs were gastrointestinal system, but they were all well-tolerated. All of the included RCTs indicated no clinically significant changes in laboratory tests or electrocardiograms in the liraglutide groups. In a word, liraglutide $3.0 \mathrm{mg} \mathrm{mg}$ once daily subcutaneously appears to provide a good balance between efficacy and side effects. Besides, Astrup A et al. conducted a 2-year open-label extension study demonstrated that liraglutide was well tolerated, sustains weight loss over 2 years and improves cardiovascular risk factors ${ }^{26}$.

The meta-analysis included the studies that all data derived from randomized double-blind, placebo-controlled trials. According to the quality-assessment scale, we conformed the quality of each study recruited in our analysis. Some limitations of the study should be mentioned. First, the number of included articles was not many. Second, the article didn't research the safety, efficacy of liraglutide with longer term. Finally, we didn't include unpublished studies. A bias may have occurred resulting from these limitations. Larger samples and more high-quality trials are needed to further investigate the efficacy and safety of liraglutide in obese, non-diabetic individuals.

\section{Conclusion}

This meta-analysis indicates that liraglutide to be an effective and safe treatment for obese, non-diabetic individuals.

\section{Acknowledgments}

Yuanshan Cui is Corresponding author of the article. Pei Zhang is first author. Yu Liu is Co-first author. Yuanshan Cui designed the research, interpreted the data and revised the paper. Pei Zhang, Yu Liu , Yuan Ren, Jie Bai and Guangzhen Zhang performed the data extraction, did Meta-analysis and drafted the paper. All of the authors approved the submitted and final versions.

\section{Funding}

None.

\section{Conflict of interest statement}

None.

\section{References}

1. Berghofer A, Pischon T, Reinhold T, et al. Obesity prevalence from a European perspective: a systematic review. BMC Public Health 2008;8:200.

2. James PT, Rigby N, Leach R, et al. The obesity epidemic, metabolic syndrome and future prevention strategies. Eur J Cardiovasc Prev Rebabil 2004;11:3-8.

3. York DA, Rossner S, Caterson I, et al. Prevention conference VII: Obesity, a worldwide epidemic related to heart disease and stroke: Group I: worldwide demographics of obesity. Circulation 2004;110:e463-470.

4. Zobel EH, Hansen TW, Rossing P, et al. Global Changes in Food Supply and the Obesity Epidemic. Curr Obes Rep 2016;5(4):449-455.

5. Bomberg E, Birch L, Endenburg N, et al. The Financial Costs, Behaviour and Psychology of Obesity: A One Health Analysis. J Comp Pathol 2017;156(4):310-325.

6. Siraj ES, Williams KJ. Another Agent for Obesity--Will This Time Be Different? N Engl J Med 2015;373(1):82-83. 7. Van Gaal LF, Mertens IL, De Block CE. Mechanisms linking obesity with cardiovascular disease. Nature 2006;444:875-880.

8. Mackay J, Mensah G. Atlas of heart disease and stroke. Geneva: World Health Organization 2004.

9. Kaukua J, Pekkarinen T, Sane T, et al. Health-related quality of life in obese outpatients losing weight with very-low-energy diet and behaviour modifi cat- 
ion: a 2-y follow-up study. Int J Obes Relat Metab Disord 2003;27:1072-1080.

10. Hassan MK, Joshi AV, Madhavan SS, et al. Obesity and health-related quality of life: a cross-sectional analysis of the US population. Int J Obes Relat Metab Disord 2003;27: 1227-1232.

11. Jensen MD, Ryan DH, Apovian CM, et al. 2013 AHA/ ACC/ TOS guideline for the management of overweight and obesity in adults: a report of the American College of Cardiology/American Heart Association Task Force on Practice Guidelines and The Obesity Society. Circulation 2014;129:Suppl 2: S102-138.

12. Gloy VL, Briel M, Bhatt DL, et al. Bariatric surgery versus non-surgical treatment for obesity: a systematic review and meta-analysis of randomised controlled trials. BMJ 2013;347:f5934.

13. Blonde L, Russell-Jones D. The safety and efficacy of liraglutide with or without oral antidiabetic drug therapy in type 2 diabetes: an overview of the LEAD 1-5 studies. Diabetes Obes Metab 2009;11:Suppl 3:26-34.

12.

14. Higgins JPT, Green S, editors. Cochrane handbook for systematic reviews of interventions, v.5.1 [updated March 2011]. Cochrane Collaboration Web site. http:// www.cochrane-handbook.org/.

15. DerSimonian R, Laird N. Meta-analysis in clinical trials. Controlled Clinical Trials 1986;7:177-188.

16. Higgins JP, Thompson SG, Deeks JJ, et al. Measuring inconsistency in meta-analyses. BMJ 2003;327:557-560.

17. Astrup A, Rossner S, Van Gaal L, et al. Effects of liraglutide in the treatment of obesity: a randomised, double-blind, placebo-controlled study. Lancet 2009;374(9701):1606-1616.

18. Kim SH, Abbasi F, Lamendola C, et al. Benefits of liraglutide treatment in overweight and obese older indi- viduals with prediabetes. Diabetes Care 2013;36(10):32763282.

19. Wadden TA, Hollander P, Klein S, et al. Weight maintenance and additional weight loss with liraglutide after low-calorie-diet-induced weight loss: the SCALE Maintenance randomized study. Int J Obes (Lond) 2013;37(11):1443-1451.

20. Pi-Sunyer X, Astrup A, Fujioka K, et al. A Randomized, Controlled Trial of $3.0 \mathrm{mg}$ of Liraglutide in Weight Management. N Engl J Med 2015;373(1):11-22.

21. Blackman A, Foster GD, Zammit G, et al. Effect of liraglutide $3.0 \mathrm{mg}$ in individuals with obesity and moderate orsevere obstructive sleep apnea: The SCALE Sleep Apnea randomized clinical trial, International Journal of Obesity accepted article preview 23 March 2016; doi: 10.1038/ ijo.2016.52.

22. Falta W, Boller R. Insulärer und insulinresistenter Diabetes. Klin Wochenschr 1931; 10: 438-443.

23. van Can J, Sloth B, Jensen CB, et al. Effects of the oncedaily GLP-1 analog liraglutide on gastric emptying, glycemic parameters, appetite and energy metabolism in obese, nondiabetic adults. Int J Obes (Lond) 2014;38:784793.

24. Flint A, Raben A, Ersboll AK, et al. The effect of physiological levels of glucagon-like peptide-1 on appetite, gastric emptying, energy and substrate metabolism in obesity. Int J Obes 2001;25:781-792.

25. Larsen PJ, Fledelius C, Knudsen LB, et al. Systemic administration of the long-acting GLP-1 derivative NN2211 induces lasting and reversible weight loss in both normal and obese rats. Diabetes 2001;50:2530-2539. 26. Astrup A, Carraro R, Finer N,et al. Safety, tolerability and sustained weight loss over 2 years with the once-daily human GLP-1 analog, liraglutide. Int J Obes. (Lond) 2012;36(6):843-854. 